\title{
The Braille Painting for Children Education: An Ecofeminism Studies
}

\section{Probosiwi}

Ahmad Dahlan University

sinaranak89@gmail.com

\begin{abstract}
Braille painting which Niken Larasati's artwork is one of the visual art medium for learning children, especially those with special needs (diffable), but this work can also be enjoyed by all people. The medium used is cowhide carved and color. The basic principle of this work is the creation of a child's world that is filled with joy, innocence, excitement packed in play activities. This work as a form of education to children with sensitivity to sensory owned by touching, feeling, speech, movement, and even combine elements of science in it as counting activities. In addition, children are required to interact with and respond to a group of playmates, natural conditions, verbal strength training, even rough motoric and fine motoric. Contextual studies using educational theory Humanistic by Abraham $\mathrm{H}$. Maslow, and finding textual studies using the theory of Nature Ecofeminism by Susan Griffin. This type of research is qualitative to understand the phenomenon or text that occurs on the object study such behavior, perception, motivation, and other actions holistic, descriptive on the specific context of natural and utilize natural methods.
\end{abstract}

Keywords: dolanan anak, humanistic, nature ecofeminism, education

\section{INTRODUCTION}

Ecofeminism is a term that emerged in 1974 triggered by a feminist from France named Françoise d' Eaubonne in his book entitled "Le feminism ou la mort" explaining his views against the oppression of women and nature. Thought d' Eaubonne unilaterally assert that freedom can't just affecting the freedom of others. Ecofeminism assumption leads to the oppression of women and nature relationship in more depth. The theory and practice by feminists included in the realm of an ecological perspective as well as all forms of solving existing problems in ecological issue.

Form of concrete action aimed feminists oppose and resist all forms of patriarchal power based on ethical environment. Forms of resistance started from criticizing the technological progress that is considered the strength of patriarchy by feminists. Advances in technology rated oppress the balance of nature and man. Any form of work or life activities have been 
pursued with advanced tools forget about the activity or the work of human hands (handmade) safer and environmentally friendly.

One of the activities of human life that has experienced a shift from traditional to modern is a game (Java: dolanan anak) who still use the objects around to be used as a tool or media play. This activity requires direct interaction between children with playmates nature. While at present, children are more inclined to like forms of computer-based games, resulting in a change of physical and mental conditions of children such as the rise of individualism higher nature because they feel have and do not want to share with other children. Dolanan anak are types of traditional children's games played in communal or together made up a lot of activity. The types include dhakon, gobag sodhor, yeye, benthik, engkling, pasaran, and others. Dolanan anak usually played by children of school age and contains the teachings of the noble values are hereditary such as tolerance, mutual respect, in line, listening to the game other friend, patient, honest to health.

Many human activities that contain elements of play or dolanan such as walking, running, jumping, squatting, crouching, stepped linked across time and space simultaneously. Dolanan child as a duplicate form of daily activities undertaken by humans, imitated by children, teach them to be able to act or behave as they should. Human activity is shown dolanan anak is being taught by generations and contains learning the identity of a society through values, thus becoming one of the cultural asset that deserves to be preserved. "Psychologically, traditional games can evoke creativity and closer to children in the natural surroundings and the Lord." It is enshrined in the type and activity dolanan anak taught noble values, the children were directed to utilize all the things that exist in the vicinity, prepare the ground before play, creative thinking, cultivate and empower all things around him.

Currently, the popularity dolanan anak are increasingly disappearing due to the proliferation of modern children's games such as video games and online games. The modern game, more seized children's self to dissolve into his own world and reduce their interaction with their surroundings. This concern itself for Niken because of lack of children character education based noble values.

Technology becomes one of the factors that affect children today are more like the modern game. Sophistication and convenience provided to make them interested in trying even have a game equipment. Children increasingly recognize dolanan anak and is caused by several reasons such as "inclusion of children's games from abroad, the increasing popularity of the spectacle on television, the spread of electronic games, the narrowing area children's playground and a reduced number of children." So that the children are more have a tendency to like modern toys have selfish tendencies, have a stronger flavor, don't want to share with other friends. Moreover, to obtain the modern game kids can access 
easily through the Internet and be required to spend more in order to be able to play when it is part of profligacy. Problems of the dematerialisation dolanan anak have long been circulating, many concerns arise later discussed in the seminar or the mass media. This phenomenon continues resonating this day because it becomes a serious problem for the mental development of children in Indonesia, therefore it has to be handled properly and thoroughly yet. Niken Larasati, an artist moved to create works of art as a form of concern for the dolanan anak.

Niken Larasati his paintings often upload photos on social media (facebook) and received responses from by Seiichi Okawa, a former Tempo magazine journalist for 25 years in Indonesia and now he is the Chairman of the "Graha Budaya Indonesia" in Japan. Their friendships made she has been to the residence and took her to a solo exhibition in the "Graha Budaya Indonesia" at Shinjuku-Ku, Tokyo, Japan in 2012 for 3 months. Before doing solo exhibition in Japan, Niken has been ever filed a solo exhibition proposal at Jogja National Museum (JNM), but it rejected on the grounds of his work was not present at the time. This solo exhibition also introduced her to some important people in Japan as one of the great teachers, Prof. Nobuko Sasaki, a senior lecturer at Daito Bunka University, Saitama, Japan, and she has chance doing workshops of 111 Javanese vocabulary sufficiently well appreciated by the public in Japan.

Dolanan anak painting which exhibited in Japan has intended to demonstrate and introduce the culture of Indonesia. Niken describe it with children figures especially on girls, this is the main attraction for the author to be studied. She said, "woman is the womb of the world and the beginning of a life because of their birth, education and compassion come." Those statements need to be explored further as it relates to the concept in the work. Additionally, Niken's desires and goals that his work is able to provide awareness to the parents (father, mother, sister, teacher, etc.) about the importance of teaching and preserving dolanan anak. She describes the dolanan anak not only on canvas but also on skin that cater for children with special needs (diffable). This work is named Braille painting.

Niken have similarity concept with Nature Ecofeminism which involving rationale women in relation to the nature like flora, fauna, soil/ earth, and society. In this case, women have an important position in favor of life without them the concept of patriarchal domination. Niken thought still need to be studied more in depth again whether the artist behavior in accordance with the ideals held or actually affected by the euphoria artists who pursue esthetic needs than social needs or be a part (instrument) by parties who have an interest and powers on behalf concern for the culture. 


\section{METHODS}

The studies of Niken Larasati's Braille painting is classified by the qualitative research, so process of reading, understanding and practice is needed. Qualitative research aims to understand the phenomenon or text that occurs on the object study such behavior, perception, motivation and other actions holistic, descriptive on the specific context of natural and utilize natural methods. Participants interview chosen by the author, among others, (1) Niken Larasati, the main object of study; (2) Tri Agus Tri Susanto Siswowiharjo, author catalogs solo exhibitions Niken in Japan in 2012 at the same time works as a lecturer and secretary of the Department of Communication Studies at STPMD "APMD" Yogyakarta as well as the author of books humor, one entitled "Merapi Never deny monarchy"; (3) Seiichi Okawa, the former Tempo journalist for 25 years in Indonesia and is now the Chairman of the Graha Budaya Indonesia in Japan.

The method used in this research is a case study in leather. Data related to the analysis and study of Nature Ecofeminism and dolanan anak obtained from a number of journals, books, studies, papers, articles and exhibition catalogs. The author takes a couple of sections that are relevant to the study of dolanan anak on a painting by Niken Larasati namely (1) The research process should be a good awareness of the "research subject" and "object of research". The characteristics of this method is the study of the reality that oppresses; (2) collective awareness on women's issues through the formulation methodology to be followed by the study of women as individuals and the position of women in the social history; (3) Women should be able to overcome individualism, careerism competition that comes amid educated men, so it is necessary to collected the experience. Data collection will be done with a literature review, interviews and direct observation. Primary data research is Braille painting inlaid on the leather. Secondary data comes from interviews with key informants, it conducted in-depth, unstructured tight, not formally done because it is done repeatedly to designated participants. Technical interviews are not always able to meet directly with participant interviews as tailored to the situation in the field include done via e-mail. Observation will be conducted by the author with a direct view to do the reading Braille painting more depth in terms of visuals, concepts or themes raised. Concept of Nature Ecofeminism rationale supported by symbolic Suzanne K. Langer to dissect the process that is in the symbolic depiction of dolanan anak. Contextual analysis uses the concept of Humanistic Abraham Maslow to find a correlation between Niken's idealism to the influence of social and cultural life in the surrounding areas in art, especially for dolanan anak. 
Data processing techniques performed by analyzing in detail the data collected through the results of a literature review, interviews and direct observation also indirectly to the works and artists. The data were analyzed qualitatively performed continuously to test some of the symptoms include space, time, behavior, artifacts and then divide it into sections in the context of data abstraction and field notes. The author also perform data reduction which serves to reinforce, clarify, create focus, taking things that are important or stakes and discard the things that do not matter, so that the data set and derive conclusions.

\section{RESULTS}

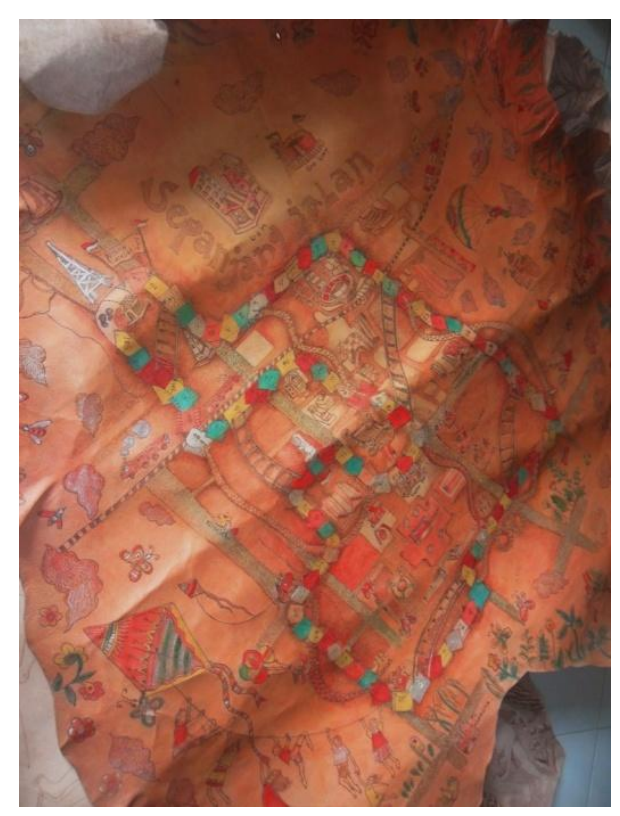

Picture 1. Niken Larasati, Sepanjang Jalan, Oxhide, 2014 (intact picture) (Photo: Probosiwi, 2014)

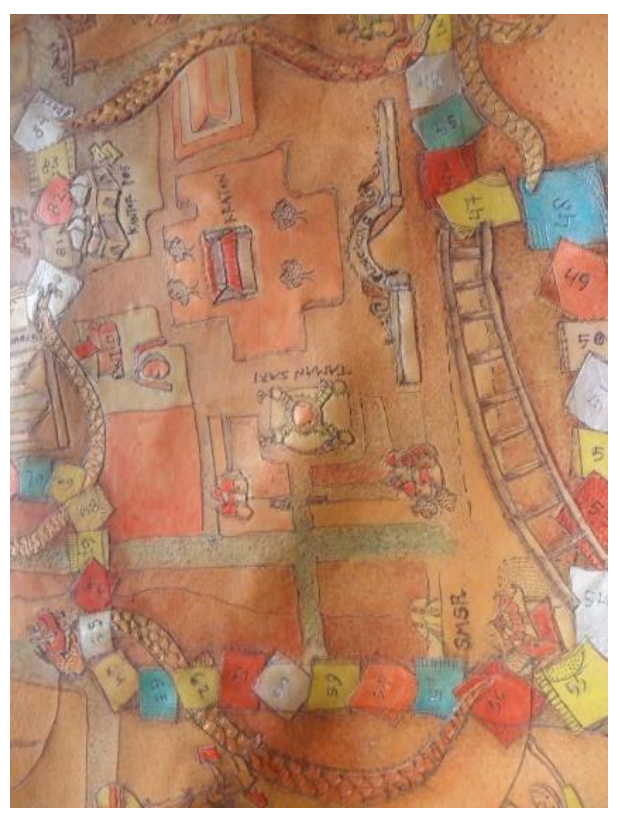

Picture 2. Detail photo (Photo: Probosiwi, 2014)

\section{Textual Analysis}

Ontological relations discussed how the actual form of the object and the relationship between these objects with the intelligence of a human, for example, through the activity of thinking, feeling and sensing. Niken Larasati ability dolanan anak has photographing with children figures that is represented in more symbols on the painting as a form power response to the phenomenon exists. The object of perception such as painting it represented by the figure of the girls as a form of meaning norm with Braille painting. Nature Feminism concept describes women and nature have the same position, nature as the representation of women and vice versa, so that all forms of destruction of nature is tantamount to the destruction of women. 
Braille painting provides an understanding of the role and function of women becomes an important part in the preservation of culture. Cultural activities are always in contact with nature and the characteristics of women who are naturally a figure of producing offspring or generation, compassionate and patient in a key form of activity refers to human behavior that should be owned as to preserve the environment (nature). Niken thought the concept is shown to describe dolanan anak either through media canvas and leather use female figures as well as the subject of preservation of cultural objects. Culture and nature have a close relationship due to the practice of human cultures interact directly with nature and involve women in it. Therefore, the author connects the philosophy of life and power of the Java community as a Javanese woman as analyzing textual approach to Braille painting. Ontological relations based on the concept of thought and concept Nature Ecofeminism which the concept implies one should always do if the flavor and the right mental attitude, so that the social life of the community will be able to achieve the principles of harmony, respect and tolerance. Dolanan anak as replica of human life in the future will be done by the children when they grow up through the traditional game. Nature Ecofeminism concept, that the philosophy of life and the power of Javanese women include women as a major figure of the preservation of cultural and natural. So that women today are no longer just put in an inferior position and not get negative stereotypes as weak. Braille painting has a symbolic power that comes from the arrangement of symbols that never existed before and is used to form a new symbol. Apart from the question of the nature of gender, authors conducted further analysis of visual Braille painting. Based on the above, by performing textual analysis of the results found that:

Niken Larasati representing dolanan anak with Braille painting which carved on the oxhide as a form of ontological relationship of women with nature and a logical expression that is symbolic traditional children's activity game that captured the artist as heritage properties of gender (feminine and masculine) and forms of nature conservation through cultural activities. The position of women and nature have an equality, then women are no longer in an inferior position under the power of patriarchy. It is a group of women who can provide orientation and education that is more intense, especially culture well done by applying the properties of the masculine and feminine gender.

Women occupy an important position in the cultural preservation through planting norms and noble values, as well as the nature that need to be explored and preserved while considering human attitude environmentally friendly that combine the properties of the feminine and masculine, in order to obtain a balance in utilizing and conserving natural.

Niken has carrying a case of cultural shift through the phenomenon of disappearance dolanan anak by including many symbols that describe positions it and herself as an artist in representing the phenomenon according to the creativity, experience and knowledge. 
In other words, the artwork has a logical expression; containing composition of sensitivity to things, emotions, thought patterns so that this knowledge can be considered as a form of expression.

\section{Contextual Analysis}

An artwork of art should be able to provide an explanation, understanding, and a sense of appreciation from the audience. The idea represented by the artist becomes more meaningful and varied perceptions. If the audience has a different physical and mental, of course the artists should be able to adjust the conditions in the environment. One is the use of media and materials from nature that can stimulate sensory powers. Niken Larasati is made the artwork that presents the activity of the senses. Children with the special needs are required to optimize the strength of stimulation of their senses, such as touch.

The Braille painting created to answer the question from the blind people who asked her how does the painting looks like and she contemplated for 16 years. It is the development of canvas painting titled dolanan anak have been made previously. Niken responds to the position of children with special needs are limited in appreciating the art, despite that this work can still be enjoyed by all people and education-based Her basic concept is the children world filled with joy, innocence, love, compassion, honesty, unity, and solidarity as well as taught by dolanan anak (the types of traditional children's games in Indonesia). It can be enjoyed by optimizing the stimulation of the senses possessed, especially in a touch. The process from the interaction of children with special needs can also be done by playing, for other audiences this work presents the feel of a memorial to an event, so that directs the audience to reflection back on what has happened.

Based on the above, Niken Larasati as a painter, the activities undertaken by her is an effort to represent ideas and presenting an alternative medium of learning through the arts for all people, especially children with special needs. It is inversely proportional to the Humanistic concept proffered by Abraham Maslow, that it was based on the framework of human needs, which then called theory of needs Maslow's invitation. Maslow proposed a theory which is based on the hierarchy of needs, where the fundamental requirement is the need for the biological, the need for security, the need for compassion, recognition and selfactualization needs. Abraham Maslow's theory, about human motivation can be applied to almost every aspect of personal and social life. Maslow also said that people were motivated by a number of basic needs that are common to the whole species, have not changed, and is derived from genetic resources or instinctive. And this concept is fundamental and unique to the theory of Maslow. The needs of human life that have been categorized by Maslow covering the needs of the physiological or biological, that is sense of security, compassion, 
an award, and self-actualization. The fourth requirement posed by Maslow, Braille paintings which made by Niken Larasati is a tangible object that can be played and used directly by children.

Basically, human beings can't be separated from other humans. Therefore, people need interaction to the surrounding environment. At this level, the concept of a Niken Larasati thinking about women is the womb of the world presumably has a correlation with the concept of Maslow's thinking that carries human needs. The following is a contextual analysis that has been done by the authors:

- Needs of Sense Security: Sense of security is to do with the observations of the behavior of adults. Dolanan anak is a replica of everyday human activities and real conducted by them. All adult behavior described and taught in it, such as the activity of the lead, responsibility, courtesy, patience, and ngemong (Java: treat, care, holding, sympathize, meal feeding, educating). Some of these behaviors is designed so that children can see and imitate their movements as a role model. In addition, children imagine when they grow up all behavior and actions are governed by ethics or rules.

- Needs of Compassion: the love involves a relationship healthy and full of affection between two people, the unity of love includes giving love and receiving love. What is taught by dolanan anak is a form of love of neighbor. Braille painting as a medium of art appreciation to children with special needs so that they get a place or an opportunity to enjoy art. This relates to the power of their images is limited or cut off by their sensory functions.

- Needs an Award: everyone has two categories namely the need for self-respect and respect of others. Self-esteem include the need for confidence, competence, mastery, achievement sufficiency, lack of dependence and freedom. While the need to be appreciated by others is prestige, recognition, acceptance, attention, status, reputation and awards. Niken captured the meaning of self-esteem of children with special needs. She saw that they have limitations, but not a thing to be pitied. Instead, they want to equality in treatment, though with a slightly different way to the others. Manifestation of concern shown by the media appreciation of art through paintings Braille is not only used by them but also the others. Braille in the work of this, the children were given the freedom to appreciate or represent figures that have been made by Niken. The Braille paintings embodies a new symbol that dolanan anak are the girls and women. Process of delivering a message to others by using the means as a second media after use symbols as the first media. The purpose of the media is painting dolanan anak while the emblem for the first media in the form of figures daughters, batik motifs, lines on the background of paintings, colors and shapes of different hair on each figure daughters. 
- Needs of Self-Actualization: everyone has to evolve to its fullest potential. Therefore, the exposure of the psychological need to grow and develop by Maslow said with selfactualization. Where actualization on Maslow's hierarchy of needs is the highest level, not because how every people can develop themselves with all the capabilities they have to be able to be fully human. From the hierarchy of its needs can be seen that the priority for fulfillment is largely determined by the level of existing needs. This means that individuals who have met the basic physiological needs are automatically would strive to meet the needs at a higher level and so on. The human who have been met will be followed by a higher fulfillment. Artistic human needs must be met for dealing with the issue of taste. How to cultivate a sense of taste and teach to children, in particular they with special needs. They can actualize their appreciation and empirical experience of art according to their sensory each abilities. The main goal of humanistic philosophy is to humanize people built through education, experience, law, culture, and art. Niken Larasati utilizes art media as steps to humanize those who have limitations and provide opportunities for self-actualization. Actually, the painting Braille can also be made by them by using media other than the skin. Niken's position as an artist who captured the lack phenomenon of sensitivity toward people with special needs.

The human exposure based on the concept of Maslow's needs can be correlated with the basic concepts of Nature Ecofeminism referring to the treatment of women and nature are comparable to reduce or even eliminate the inferiority stereotypes masculine traits of the feminine gender. At least Niken did not seek to work can be enjoyed by all people, and the rest pay special attention to them. She arrangement as a woman, wife, mother and artist which not many women painters in the world can do.

\section{REFERENCES}

Fakih, Mansour. 2010. Analisis Gender dan Transformasi Sosial. Yogyakarta: Pustaka Pelajar.

Griffin, Susan. 1978. Woman and Nature. USA: Harper \& Row.

Huizinga, Johan. 1949. Homo Ludens Study of the Play. London: Routledge \& Kegan Paul Ltd.

Langer, Suzanne. K (Terj. FX. Widaryanto). 2006. Problematika Seni. Bandung: Sunan Ambu Press.

Maslow, Abraham. 1993. The Farther Reaches of Human Nature. United States of America: Library of Congress Cataloging in Publication Data.

Moleong, Lexy. 2010. Metodologi Penelitian Kualitatif(Edisi Revisi). Bandung: PT. Remaja Rosdakarya. 
Tri Agus Susanto Siswowiharjo, Writer, Lecture and Secretary of the Study Programme of Communication at STPMD “APMD” Yogyakarta, "Personal Interview", $22^{\text {nd }}$ of June 2015 at 11:26 a.m.

Seiichi Okawa, the Chairman of "Graha Budaya Indonesia" in Japan and the former TEMPO Magazine Journalist for 25 years, "Personal Interview", via email (okawa@mxg.mesh.ne.jp) 9 th of July 2015 at 10.32 a.m.

https://psikologiuhuy.wordpress.com/2010/04/08/teori-kepribadian-abraham-haroldmaslow/ (accessed $5^{\text {th }}$ of August at 03.18 a.m.) 